\title{
ACTH-INDUCED SUBDURAL HEMATOMA
}

Subdural hematoma is reported in two infants with West syndrome treated with low-dose synthetic ACTH $(0.01 \mathrm{mg} ; 0.4 \mathrm{IU} / \mathrm{kg} /$ day; total doses: $0.24 \mathrm{mg} ; 9.6 \mathrm{IU}$ and $0.26 \mathrm{mg} ; 10.4 \mathrm{IU})$ at Shiga Medical Center for Children, Moriyama, Japan. Both patients had first received a combination of vitamin B6 and valproate without benefit. Infantile spasms and hypsarrhythmia in the EEGs responded to ACTH. MRIs showed progressive cerebral atrophy and subdural hematoma after the 24th and 26th injection. The hematoma in one infant resolved spontaneously after ACTH was stopped, and surgical suction was required in the other. Mild hypertension and pneumonia occurred as additional complications of ACTH therapy in one. (Ito M, Miyajima T, Fujii T, Okuno T. Subdural hematoma during low-dose ACTH therapy in patients with West syndrome. Neurology June (2 of 2) 2000;54:2346-2347). (Reprints: Dr Masatoshi Ito, Department of Pediatrics, Shiga Medical Ceneter for Children, 5-7-30 Moriyama, Moriyama-shi 524-0022, Japan).

COMMENT. Cerebral shrinkage as a complication of ACTH therapy for infantile spasms has been correlated with the total dose, and the incidence of adverse reactions with the synthetic preparation may be higher than that following natural ACTH. The above report shows that even low-dose ACTH may induce brain shrinkage that results in subdural hematoma.

In Japan, initial treatment with vitamin B6 followed by a combination of vitamin B6 and valproate is preferred, and ACTH is the third treatment of choice. (Ito M, Seki T, Takuma Y. Current therapy for West syndrome in Japan. I Child Neurol June 2000;15:424-428). Vitamin B6 is started at $10-50 \mathrm{mg} / \mathrm{kg} / \mathrm{day}$ and the dose is increased by $10 \mathrm{mg} / \mathrm{kg} /$ day every 3 to 5 days. The maintenance dose is usually $50 \mathrm{mg} / \mathrm{kg} /$ day.

\section{KETOGENIC DIET-INDUCED CARDIOMYOPATHY}

Prolonged QT interval $(>450)$ is reported in 3 of 20 pediatric epilepsy patients (mean age $9.8+/-4.7$ years) treated with the ketogenic diet at the University of Cincinnati, OH. The duration of the diet was $13+/-8$ months, and the initial fat to nonfat calorie ratio was $4: 1$. Vitamins, minerals, selenium, and carnitine supplements were added. Two patients with QT intervals $>500$ had left atrial and ventricular enlargement. Calcium levels were normal. Pronged QT was significantly correlated with low serum bicarbonate and high betahydroxybutyrate. When the diet was discontinued in one patient, the QT abnormality and cardiomyopathy resolved. (Best TH, Franz DN, Gilbert DL, Nelson DP, Epstein MR. Cardiac complications in pediatric patients on the ketogenic diet. Neurology June (2 of 2) 2000;54:2328-2330). (Reprints: Dr DN Franz, Department of Neurology, Children's Hospital, 3333 Burnet Ave, Cincinnati, OH 45229).

COMMENT. Children treated with the ketogenic diet in the 4:1/ketogenic:antiketogenic ratio should receive ECGs and echocardiograms before and during therapy. This cardiac complication is a further indication of the need to reassess the relatively high fat content of the Hopkins ketogenic diet. As previously indicated, the original Mayo Clinic method of introduction of the diet, with much lower fat/CH ratios, is effective and with fewer side reactions (Ped Neur Briefs August 1998;12:61). 